\title{
Prevalence and Risk Factors of Mild Cognitive Impairment (MCI) among the Elderly of Guwahati City, Assam: A Cross-sectional Study
}

\author{
Anku Moni Saikia, Vinoth Rajendran*
}

\begin{abstract}
Background: WHO defines "Healthy Ageing" as the process of developing and maintaining the functional ability that enables well-being in older age. The population among the elderly is growing constantly and with increased life expectancy, there is a tremendous increase in morbidity and disability. $\mathrm{MCl}$ is an intermediate stage between dementia and cognitive decline in normal individuals. It is important to understand various factors associated with $\mathrm{MCl}$ to develop preventive strategies. Objectives: To find out the prevalence and risk factors of mild cognitive impairment among the elderly in Guwahati, Assam. Settings and Design: A communitybased, cross-sectional study was conducted in Guwahati City. Materials and Methods: This study was conducted among the elderly of 60 years or above of both the sexes in Guwahati City. Considering $p=14.89 \%$, sample size was calculated as 576 elderly. Fifty percent of the total wards i.e. 16 wards were selected randomly and 36 elderly were selected from each ward. The data were collected using a predesigned and pretested schedule, Hindi Mini-Mental State Examination (HMMSE) scale for mild cognitive impairment, Activities of Daily Living (ADL) of Katz Index and Instrumental Activities of Daily Living (IADL) of Lawton Index for functional status. Results: The prevalence of $\mathrm{MCl}$ was $24.2 \%$. The risk factors like gender, living arrangement, education, alcohol consumption, constipation, sleep disturbance were associated with mild cognitive impairment on binary logistic regression. Conclusion: A very high prevalence of $\mathrm{MCl}$ was found among the elderly. Various modifiable risk factors like living arrangement, education, alcohol consumption, sleep disturbance and depression were found to be associated with $\mathrm{MCl}$ and it can be targeted to prevent $\mathrm{MCl}$.

Key words: Prevalence, Mild cognitive impairment, Elderly, HMMSE, Assam.

Key Messages: The prevalence of $\mathrm{MCl}$ was found high among the elderly which requires mandatory inclusion of screening for cognitive function.
\end{abstract}

\section{Anku Moni Saikia, Vinoth Rajendran*}

Department of Community Medicine, Gauhati Medical College and Hospital (GMCH). Bhangagarh, Guwahati, Assam, INDIA.

\section{Correspondence}

\section{Dr. Vinoth Rajendran}

Department of Community Medicine,

Gauhati Medical College and Hospital

(GMCH). Bhangagarh-781032, Guwahati,

Assam, INDIA.

Phone no: +91 9597459322

Email: rvinoth351@gmail.com

\section{History}

- Submission Date: 27-11-2019

- Revised Date: 20-04-2020

- Accepted Date: 15-05-2020

DOI : 10.5530/ijmedph.2020.2.16

Article Available online

http://www.ijmedph.org/v10/i2

\section{Copyright}

(C) 2020 Phcog.Net. This is an openaccess article distributed under the terms of the Creative Commons Attribution 4.0 International license.

\section{INTRODUCTION}

Along with the world, India is also experiencing the stage of demographic transition. The elderly population has increased from $5.6 \%$ in 1961 to $8.6 \%$ in $2011 .{ }^{1}$ It is also projected to raise by $64 \%$ by $2030 .{ }^{2}$ The vulnerability to different diseases increases with increasing life expectancy. This leads to various types of morbidities and disabilities. One of the important causes of disability is dementia. This puts a huge burden on the family, the caregivers and the society as a whole. There are many causes of dementia in the elderly. However, Alzheimer Dementia (AD) is the most common cause in old age. Dementia is the broad term used for a decline in cognitive ability that is severe enough to restrict with daily life. Mild cognitive impairment (MCI) is an intermediate stage between dementia and normal cognition. It can involve problems with memory, language, thinking and judgment that are greater than normal age-related changes but the person's day to day activities are not interfered. Hence, it is under-reported or unrecognised.
More than half of them with mild cognitive impairment progress to dementia within 5 years while some seem to remain stable or return to normal over time. ${ }^{3}$ Early diagnosis of MCI may help in decreasing the incidence of MCI.

Studies on MCI are limited from India and there are no published studies from this part of the country. There are multiple risk factors associated with mild cognitive impairment. Though MCI is prevalent among the elderly, this issue is not getting due priority. MCI is a reversible stage, so identifying MCI at the early stage and Effective intervention will help in the prevention of Alzheimer's disease. So the present study has been conducted to find out the prevalence and risk factors of mild cognitive impairment among the elderly in Guwahati, Assam.

\section{MATERIALS AND METHODS}

This community-based, cross-sectional study was conducted among the elderly of 60 years or above of 
both the sexes in Guwahati City, Assam from July 2018 to August 2019. Those who were residing in the study area permanently for more than 1 year preceding the study and those who were giving consent to participate were included in the study. Critically ill elderly, institution bound elderly, elderly who failed to comprehend the question due to severe hearing loss, severely depressed elderly and known or diagnosed cases of Parkinson's disease (PD) were excluded from the study.

Considering $\mathrm{p}=14.89 \%{ }^{4}$ and applying the formula, $\mathrm{n}=4 \mathrm{pq} / \mathrm{L}^{2}$, the minimum sample size was calculated as 572 for this study. Fifty percent of the total wards i.e. 16 wards were selected randomly from the list of the ward from Guwahati Municipal Corporation. From each ward 36 elderly were selected, making a total of 576 for this study. Thirty-six households were randomly selected using random number table assuming that each household would have one elderly. All the elderly in a household who were fulfilling the inclusion criteria were included in this study. The information obtained is verified with the close family member or caregiver as and when necessary.

The data were collected using a predesigned and pretested schedule. Different variables like type of diet, smoking status, alcohol consumption, diabetes, hypertension, functional status, social and leisure activities and depression were included in this study. MCI was screened using Hindi Mini-Mental State Examination (HMMSE) scale..$^{5-7}$ Depression and functional status were assessed using 15 Geriatric Depression Scale (15GDS), ${ }^{8,9}$ Activities ofDailyLiving(ADL) of KatzIndexand Instrumental Activities of Daily Living (IADL) of Lawton Index were used. ${ }^{10,11}$ Classification of smoking status was done as per the Centers for Disease Control and Prevention (CDC) guidelines. ${ }^{12}$ Hypertension was diagnosed using JNC 8 criteria. ${ }^{13}$ Fasting blood sugar estimation was measured by Accu chek active blood glucose meter and classified as per the WHO classification. $^{14}$

Operational definitions were made for classifying individuals based on the type of diet, sleep disturbance, alcohol consumption and social and leisure activities. Those who have been taking a vegetarian diet for the last 6 months were considered vegetarian and vice versa. Regarding alcohol users, those who have taken fewer than 12 drinks in a lifetime were taken as never users, Ever users of alcohol includes both former and current users. Those who have taken at least 12 drinks in any one year in a lifetime but no drinks in the past year were taken as former users. Those who have taken more than 12 drinks in a lifetime and who have taken at least one or a few drinks in the past year were taken as current users. Social and leisure engagement was assessed based on the type of activities and the duration of hours spent per week. The types of activities include television viewing, hobbies/ crafts, participating in community work, participating in social gatherings/ religious place, visiting friends/ neighbours and interaction with family members. For each activity, one point was given. Out of a total score of 6 , those who have scored more than 2 were further assessed for the duration of social and leisure engagement. Those whose duration was more than $5 \mathrm{hrs}$ per week were considered adequate in social and leisure engagement.

The data collected were analyzed using IBM SPSS Statistics version 25. Proportions were calculated for different study variables. The chi-square test was used for the analysis of categorical variables. The criteria of significance used in the study were $p<0.05$. Binary logistic regression analysis was used for the different study variables.

\section{RESULTS}

The prevalence of MCI was $22.4 \%$ among the elderly. Among the elderly participants (576) interviewed, majority (62.5\%) were in the age group of 60-69 years. Among the elderly with mild cognitive impairment, females were found to be comparatively higher than the males. (Table 1)
While assessing the relationship between various risk factors and $\mathrm{MCI}$, the risk factors like smoking, functional status, social leisure engagement, depression, sleep disturbance were found to be significant. (Table 2)

The variables that were found significantly associated with mild cognitive impairment were further analyzed with binary logistic regression. The living arrangement, education status, alcohol consumption and depression was found to be a potential risk factor for mild cognitive impairment. (Table 3)

\section{DISCUSSION}

The prevalence of mild cognitive impairment was found to be high among the elderly. However, it could be viewed as the tip of an iceberg as a decline in cognition may be perceived as a part of normal ageing. Further study with bigger sample size is required to assess the MCI. Similarly, a high prevalence of MCI (26.06\%) was found among community-dwelling older adults in a South India metropolitan area. ${ }^{15}$ Population-based studies in older adults reported a prevalence of MCI ranging from $11 \%$ to $17 \%$, higher than previously reported prevalence of dementia $(6-8 \%){ }^{16-19}$

MCI and age were not significantly associated in the present study and this could be due to more number of the sample population in the age

\begin{tabular}{|c|c|c|c|c|c|c|c|}
\hline \multirow{3}{*}{$\begin{array}{l}\text { Socio- } \\
\text { demographic } \\
\text { factors }\end{array}$} & \multicolumn{4}{|c|}{ Mild cognitive impairment } & \multirow{3}{*}{ Total } & \multirow{3}{*}{$\%$} & \multirow{3}{*}{$P$-value } \\
\hline & \multicolumn{2}{|c|}{ Absent $(n=447)$} & \multicolumn{2}{|c|}{$\begin{array}{l}\text { Present } \\
(n=129)\end{array}$} & & & \\
\hline & Count & $\%$ & Count & $\%$ & & & \\
\hline \multicolumn{8}{|c|}{ Age } \\
\hline $60-69$ years & $285(63.8)$ & 79.2 & $75(58.1)$ & 20.8 & $360(62.5)$ & 100 & \multirow{3}{*}{0.339} \\
\hline $70-79$ years & $126(28.2)$ & 73.7 & $45(34.9)$ & 26.3 & $171(29.7)$ & 100 & \\
\hline$>80$ years & $36(8)$ & 80.0 & $9(7.0)$ & 20.0 & $45(7.8)$ & 100 & \\
\hline \multicolumn{8}{|c|}{ Gender } \\
\hline Male & $240(53.7)$ & 83.3 & $48(37.2)$ & 16.7 & $288(50.0)$ & 100 & \multirow{2}{*}{$.001^{*}$} \\
\hline Female & $207(46.3)$ & 71.9 & $81(62.7)$ & 28.1 & $288(50.0)$ & 100 & \\
\hline \multicolumn{8}{|c|}{ Living arrangement } \\
\hline $\begin{array}{l}\text { With relatives } \\
\text { or caregivers }\end{array}$ & $6(1.3)$ & 100.0 & - & - & $6(1.0)$ & 100 & \\
\hline With spouse & $223(49.9)$ & 84.2 & $42(32.6)$ & 15.8 & $265(46.0)$ & 100 & \\
\hline Alone & $45(10.1)$ & 78.9 & $12(9.3)$ & 21.1 & $57(9.9)$ & 100 & $.000^{*}$ \\
\hline $\begin{array}{l}\text { With children } \\
\text { and spouse }\end{array}$ & $116(26.0)$ & 79.5 & $30(23.3)$ & 20.5 & $146(25.3)$ & 100 & \\
\hline With children & $57(12.8)$ & 55.9 & $45(34.9)$ & 44.1 & $102(17.7)$ & 100 & \\
\hline \multicolumn{8}{|c|}{ Education } \\
\hline Professional & $17(3.8)$ & 100 & - & - & $17(3.0)$ & 100 & \multirow{7}{*}{$<0.000^{*}$} \\
\hline $\begin{array}{c}\text { Graduates and } \\
\text { above }\end{array}$ & $157(35.1)$ & 89.7 & $18(14.0)$ & 10.3 & $175(30.4)$ & 100 & \\
\hline High School & $27(6.0)$ & 81.8 & $6(4.7)$ & 18.2 & $33(5.7)$ & 100 & \\
\hline Matriculate & $39(8.7)$ & 81.3 & $9(7.0)$ & 18.8 & $48(8.3)$ & 100 & \\
\hline Middle School & $108(24.2)$ & 80.0 & $27(20.9)$ & 20.0 & $135(23.4)$ & 100 & \\
\hline $\begin{array}{l}\text { Primary } \\
\text { School }\end{array}$ & $39(8.7)$ & 61.9 & $24(18.6)$ & 38.1 & $63(10.9)$ & 100 & \\
\hline Illiterate & $60(13.4)$ & 57.1 & $45(34.9)$ & 42.9 & $105(18.2)$ & 100 & \\
\hline
\end{tabular}

Figures in parenthesis represent the column-wise percentage. 


\begin{tabular}{|c|c|c|c|c|c|c|c|}
\hline \multirow{3}{*}{ Risk factors } & \multicolumn{4}{|c|}{ Mild Cognitive impairment } & \multirow{3}{*}{ Total } & \multirow{3}{*}{$\%$} & \multirow{3}{*}{$P$-value } \\
\hline & \multicolumn{2}{|c|}{ Absent $(n=447)$} & \multicolumn{2}{|c|}{ Present $(n=129)$} & & & \\
\hline & No.(\%) & $\%$ & No.(\%) & $\%$ & & & \\
\hline \multicolumn{8}{|c|}{ Type of diet } \\
\hline Vegetarian & $54(12.1)$ & 78.3 & $15(11.6)$ & 21.7 & $69(12.0)$ & 100 & \multirow[b]{2}{*}{0.889} \\
\hline $\begin{array}{c}\text { Non- } \\
\text { vegetarian }\end{array}$ & $393(87.9)$ & 77.5 & $114(88.4)$ & 22.5 & $507(88.0)$ & 100 & \\
\hline \multicolumn{8}{|c|}{ Smoking status } \\
\hline Ex-user & $75(16.8)$ & 89.3 & $9(7.0)$ & 10.7 & $84(14.6)$ & 100 & \multirow{3}{*}{$.013^{*}$} \\
\hline Current user & $39(8.7)$ & 81.3 & $9(7.0)$ & 18.8 & $48(8.3)$ & 100 & \\
\hline Never user & $333(74.5)$ & 75.0 & $111(86.0)$ & 25.0 & $444(77.1)$ & 100 & \\
\hline \multicolumn{8}{|c|}{ Alcohol users } \\
\hline Current user & $102(22.8)$ & 82.9 & $21(16.3)$ & 17.1 & $123(21.4)$ & 100 & \multirow{3}{*}{$.002^{*}$} \\
\hline Never user & $213(47.7)$ & 81.3 & $49(38.0)$ & 18.7 & $262(45.5)$ & 100 & \\
\hline Ex-user & $132(29.5)$ & 69.1 & $59(45.7)$ & 30.9 & 191(33.2) & 100 & \\
\hline \multicolumn{8}{|c|}{ Diabetes } \\
\hline No & $327(73.2)$ & 76.8 & $99(76.7)$ & 23.2 & $426(74.0)$ & 100 & \multirow[t]{2}{*}{0.413} \\
\hline Yes & $120(26.8)$ & 80.0 & $30(23.3)$ & 20.0 & $150(26.0)$ & 100 & \\
\hline \multicolumn{8}{|c|}{ Hypertension } \\
\hline No & $213(47.7)$ & 78.9 & $57(44.2)$ & 21.1 & $270(46.9)$ & 100 & \multirow[t]{2}{*}{0.487} \\
\hline Yes & $234(52.3)$ & 76.5 & $72(55.8)$ & 23.5 & $306(53.1)$ & 100 & \\
\hline \multicolumn{8}{|c|}{ ADL status } \\
\hline Intact & $443(99.1)$ & 78.5 & $121(93.8)$ & 21.5 & $564(97.9)$ & 100 & \multirow{2}{*}{$.000^{*}$} \\
\hline Not intact & $4(0.9)$ & 33.3 & $8(6.2)$ & 66.7 & $12(2.1)$ & 100 & \\
\hline \multicolumn{8}{|c|}{ IADL status } \\
\hline Intact & $438(98.0)$ & 79.2 & $115(89.1)$ & 20.8 & $553(96.0)$ & 100 & \multirow{2}{*}{$.000^{*}$} \\
\hline Not intact & $9(2.0)$ & 39.1 & $14(10.9)$ & 60.9 & $23(4.0)$ & 100 & \\
\hline \multicolumn{8}{|c|}{ Social and leisure engagement } \\
\hline Adequate & $246(55.0)$ & 82.8 & $51(39.5)$ & 17.2 & $297(51.6)$ & 100 & \multirow{2}{*}{$.002^{*}$} \\
\hline Inadequate & $201(45.0)$ & 72.0 & $78(60.5)$ & 28.0 & $279(48.4)$ & 100 & \\
\hline \multicolumn{8}{|c|}{ Sleep disturbance } \\
\hline Adequate & $129(28.9)$ & 66.2 & $66(51.2)$ & 33.8 & 195(33.9) & 100 & \multirow{2}{*}{$.000^{*}$} \\
\hline Inadequate & $318(71.1)$ & 83.5 & $63(48.8)$ & 16.5 & $381(66.1)$ & 100 & \\
\hline \multicolumn{8}{|c|}{ Depression } \\
\hline Absent & $391(87.5)$ & 93.5 & $27(20.9)$ & 6.5 & $418(72.6)$ & 100 & \multirow{2}{*}{$.000^{*}$} \\
\hline Present & $56(12.5)$ & 35.4 & $102(79.1)$ & 64.6 & $158(27.4)$ & 100 & \\
\hline
\end{tabular}

Figures in parenthesis represent the column-wise percentage.

group of 60-69 years. These findings were contrary to the other studies, where they found that the increase in the incidence of MCI with age is not unexpected. ${ }^{20,21}$

Among the elderly, low education were more likely to have cognitive problems than their counterparts. Education is shown to be a protective factor in Alzheimer's disease. The findings are similar to the previous studies that have also shown that low education is associated with increased risk of cognitive impairment. ${ }^{22,23}$ People with high education level may adopt healthier lifestyle that is related to good cognitive function. ${ }^{23}$ The alcohol consumption among the elderly had a significant association with MCI. The significant relationship between alcohol intake and MCI

\begin{tabular}{|c|c|c|c|c|c|}
\hline Risks factors & B & S.E. & df & Sig. & $\operatorname{Exp}(B)$ \\
\hline Gender & 0.236 & 0.378 & 1 & 0.533 & 1.266 \\
\hline \multicolumn{6}{|c|}{ Living arrangement (with relatives or care-givers) a } \\
\hline With spouse & -18.493 & 14828.745 & 1 & 0.999 & 0.000 \\
\hline Alone & -0.176 & 0.461 & 1 & 0.702 & 0.838 \\
\hline With children and spouse & -2.075 & 0.637 & 1 & 0.001 & 0.126 \\
\hline With children & -1.611 & 0.543 & 1 & 0.003 & 0.200 \\
\hline \multicolumn{6}{|c|}{ Education (Professional) a } \\
\hline Graduates and above & -19.121 & 9284.277 & 1 & 0.998 & 0.000 \\
\hline High school & -1.241 & 0.515 & 1 & 0.016 & 0.289 \\
\hline Matriculate & -1.427 & 0.753 & 1 & 0.058 & 0.240 \\
\hline Middle school & -1.579 & 0.641 & 1 & 0.014 & 0.206 \\
\hline Primary school & -1.378 & 0.455 & 1 & 0.002 & 0.252 \\
\hline Illiterate & -0.256 & 0.521 & 1 & 0.624 & 0.775 \\
\hline Type of diet & -0.337 & 0.461 & 1 & 0.465 & 0.714 \\
\hline \multicolumn{6}{|c|}{ Smoking status (Ex-user) a } \\
\hline Current user & -0.423 & 0.584 & 1 & 0.469 & 0.655 \\
\hline Never user & -0.596 & 0.587 & 1 & 0.309 & 0.551 \\
\hline \multicolumn{6}{|c|}{ Alcohol consumption (Current user) a } \\
\hline Never user & -1.052 & 0.481 & 1 & 0.029 & 0.349 \\
\hline Ex-user & -0.019 & 0.379 & 1 & 0.961 & 0.981 \\
\hline ADL status & -0.512 & 1.116 & 1 & 0.646 & 0.599 \\
\hline IADL status & 0.303 & 0.872 & 1 & 0.728 & 1.354 \\
\hline Social and leisure activities & -0.512 & 0.317 & 1 & 0.106 & 0.599 \\
\hline Sleep disturbance & 1.382 & .341 & 1 & .000 & 3.984 \\
\hline Depression & -4.297 & 0.436 & 1 & 0.000 & 0.014 \\
\hline
\end{tabular}

${ }^{a}$ Reference group

was in conformity with various studies done across the globe. Light to moderate drinking may be associated with the decreased danger of dementia and Alzheimer's disease, but there is no definite decreased risk of cognitive decrease and pre-dementia. ${ }^{24,25}$ However, the current study could not assess the type of alcohol consumed by the elderly.

Sleep disturbances was found to be a risk factor for mild cognitive impairment. On contrary, individuals with Alzheimer's disease and mild cognitive impairment have the same frequency of sleep disorders. But mild cognitive impairment was not significantly associated with sleepdisordered breathing, behaviour disorder, restless legs syndrome and excessive daytime sleepiness. ${ }^{26}$ This variation may be due to the reason that the participants taken in their study may have problem in remembering the duration of sleep, since it was not assessed considering the cross-sectional study design.

Depression was significantly associated with mild cognitive impairment. It could be attributed due to the less time spent in social and leisure time activities which may indirectly influence the mild cognitive impairment. It is in conformity to the findings of other studies wherethey found that depression increases the risk of incident $\mathrm{MCI}, \mathrm{AD}$ and vascular dementia. ${ }^{27,28}$

The study has got few limitations like the tools with more accuracies like Addenbrooke's Cognitive Examination-3 (ACE-3) and Montreal Cognitive Assessment (MoCA)were not taken due to resource constraints, many 
variables where lifetime exposure influences MCI (smoking, alcohol use) could not be assessed due to the cross-sectional study design and assessment of variables like diet could not be assessed in depth because of resource constraint.

\section{CONCLUSION}

A high prevalence of mild cognitive impairment was found among the elderly which requires mandatory inclusion of screening for cognitive impairment in all geriatric assessment. The comprehensive assessment should also include screening for depression as it was significant with MCI. Proper counselling and education regarding use of alcohol has to be done as a life-course approach.

\section{ACKNOWLEDGEMENT}

The authors would like to thank all study participants.

\section{CONFLICT OF INTEREST}

The authors declare no conflict of interest.

\section{ABBREVIATIONS}

MCI: Mild Cognitive impairment; HMMSE: Hindi Mini-Mental State Examination; ADL: Activities of Daily Living; IADL: Instrumental Activities of Daily Living; AD: Alzheimer Dementia; PD: Parkinson's Disease; 15 GDS: 15 Geriatric Depression Scale; CDC: Centers for Disease Control and Prevention; ACE-3: Adden brooke's Cognitive Examination-3; MoCA: Montreal Cognitive Assessment.

\section{REFERENCES}

1. Mospi. nic. in [updated 2019; Cited 2019Sep 4]Available at:http://mospi.nic.in/ sites/default/files/publication_reports/ElderlyinIndia_2016.pdf.

2. Un.org[Internet]. [updated 2019;cited 2019Sep6]. Available from: https://www. un.org/en/development/desa/population/publications/pdf/ageing/WPA2015_Report.pdf

3. Gauthier S, Reisberg B, Zaudig M, Petersen RC, Ritchie K, Broich K, et al. Mildcognitive impairment. The Lancet. 2006;367(9518):1262-70.

4. Das SK, Bose P, Biswas A, Dutt A, Banerjee TK, Hazra A, et al. An epidemiologic study of mild cognitive impairment in Kolkata, India. Neurology. 2007:68(23):2019-26.

5. Shim YS, Yang DW, Kim HJ, Park YH, Kim S. Characteristic differences in the mini-mental state examination used in Asian countries. BMC Neurology. 2017;17(1):141.

6. Tsolaki M, lakovidou V, Navrozidou H, Aminta M, Pantazi T, Kazis A. Hindi Mental State Examination(HMSE) as a screening test for illiterate demented patients. International Journal of Geriatric Psychiatry. 2000;15(7):662-4.

7. Tiwari SC, Tripathi RK, Kumar A. Applicability of the Mini-mental State Examination (MMSE) and the Hindi Mental State Examination (HMSE) to the urban elderly in India: A pilot study. International Psychogeriatrics. 2009;21(1):123-8.

8. DeCraen AJ, Heeren TJ, Gussekloo J. Accuracy of the 15- item geriatric depression scale (GDS- 15) in a community sample of the oldest old. International Journal of Geriatric Psychiatry. 2003;18(1):63-6.
9. Prakash O, Gupta LN, Singh VB, Nagarajarao G. Applicability of 15-item Geriatric Depression Scale to detect depression in elderly medical out patients. Asian Journal of Psychiatry. 2009;2(2):63-5.

10. Shelkey $M$, Wallace $M$. Katz index of independence in activities of daily living (ADL). International Journal of Older People Nursing. 2000:2(3):204-12.

11. Mathuranath PS, George A, Cherian PJ, Mathew R, Sarma PS. Instrumental activities of daily living scale for dementia screening in elderly people. International Psychogeriatrics. 2005;17(3):461-74

12. Cdc.gov. 2019. NHIS - Adult Tobacco Use - Glossary. [cited 2019 Nov 16]. Available from: https://www.cdc.gov/nchs/nhis/tobacco/tobacco_glossary.htm

13. The JNC 8 Hypertension Guidelines: An In-Depth Guide. AJMC[cited 2019 Sep 6]. Available from: https://wWw.ajmc.com/journals/evidence-based-diabetesmanagement/2014/january-2014/the-jnc-8-hypertension-guidelines-an-indepth- guide

14. Apps. who. int. [cited 2 September 2019]. Available from: https://apps.who. int/iris/bitstream/handle/10665/325182/9789241515702- eng. pdf? sequence $=1$ andisAllowed $=y$

15. Mohan D, lype T, Varghese S, Usha A, Mohan M. A cross-sectional study to assess prevalence and factors associated with mild cognitive impairment among older adults in an urban area of Kerala, South India. BMJ Open. 2019;9(3):e025473.

16. DiCarlo A, Baldereschi M, Amaducci L, Maggi S, Grigoletto F, ScarlatoG, et al. Italian Longitudinal Study on Aging Working Group. Cognitive impairment without dementia in older people: Prevalence, vascular risk factors, impact on disability. The Italian Longitudinal Study on Aging. Journal of the American Geriatrics Society. 2000;48(7):775-82.

17. Ganguli M, Dodge HH, Shen C, DeKosky ST. Mild cognitive impairment, amnestic type: An epidemiologic study. Neurology. 2004;63(1):115-21.

18. Graham JE, Rockwood K, Beattie BL, Eastwood R, Gauthier S, Tuokko H, et al. Prevalence and severity of cognitive impairment with and without dementia in an elderly population. The Lancet. 1997;349(9068):1793-6.

19. Ritchie K, Artero S, Touchon J. Classification criteria for mild cognitive impairment: A population-based validation study. Neurology. 2001;56(1):37-42.

20. Busse A, Hensel A, Gühne U, Angermeyer MC, Riedel-Heller SG. Mild cognitive impairment: Long-term course of four clinical subtypes. Neurology 2006:67(12):2176-85.

21. Luis CA, Barker WW, Loewenstein DA, Crum TA, Rogaeva E, Kawarai T, et al. Conversion to dementia among two groups with cognitive impairment. Dementia and Geriatric Cognitive Disorders. 2004;18(3-4):307-13

22. Anderson TM, Sachdev PS, Brodaty H, Trollor JN andrews G. Effects of sociodemographic and health variables on Mini-Mental State Exam scores in older Australians. The American Journal of Geriatric Psychiatry. 2007;15(6):467-76.

23. Hooren SAV Valentiin AM, Bosma H, Ponds RW, Boxtel MPV Jolles J. Cognitive functioning in healthy older adults aged 64-81: A cohort study into the effects of age, sex and education. Aging, Neuropsychology and Cognition. 2007;14(1):40-54

24. Launer LJ, Feskens EJ, Kalmijn S, Kromhout D. Smoking, drinking and thinking: the zutphen elderly study: The zutphen elderly study. American Journal of Epidemiology. 1996;143(3):219-27.

25. Panza F, Frisardi V, Seripa D, Logroscino G, Santamato A, Imbimbo BP, et al. Alcohol consumption in mild cognitive impairment and dementia: harmful or neuroprotective?. International Journal of Geriatric Psychiatry. 2012;27(12):1218-38

26. Yaffe K, Laffan AM, Harrison SL, Redline S, Spira AP, Ensrud KE, et al. Sleepdisordered breathing, hypoxia and risk of mild cognitive impairment and dementia in older women. Jama. 2011;306(6):613-9.

27. Diniz BS, Butters MA, Albert SM, Dew MA, Reynolds CF. Late-life depression and risk of vascular dementia and Alzheimer's disease: Systematic review and meta-analysis of community-based cohort studies. The British Journal of Psychiatry. 2013;202(5):329-35.

28. Geda YE, Ragossnig M, Roberts LA, Roberts RO, Pankratz VS, Christianson TJ, et al. Caloric intake, aging and mild cognitive impairment: a population-based study. Journal of Alzheimer's disease. 2013:34(2):501-7. 